\title{
Rapid purification of human peripheral blood monocytes by centrifugation through Ficoll-Hypaque and Sepracell-MN
}

\author{
Margret C.M. Vissers, Sherry A. Jester and Joseph C. Fantone \\ Department of Pathology, The University of Michigan Medical School, Ann Arbor, Michigan 48109-0602, U.S.A.
}

(Received 30 November 1987, revised received 12 January 1988, accepted 13 January 1988)

We have developed a rapid and simple method for isolating human peripheral blood monocytes in suspension. The procedure combines two separation media and involves isolation of the mononuclear cells by centrifugation through Ficoll-Hypaque followed by purification of the monocytes using Sepracell-MN, a colloidal silica-based medium. The final cell population contained approximately $90 \%$ monocytes with good functional ability. The contaminating cells were lymphocytes. Viability was always $\geqq 99 \%$ with $90 \%$ recovery of the monocytes from the mononuclear cells.

Key words: Monocyte, human; Sepracell-MN; Isolation

\section{Introduction}

Peripheral blood monocytes are the precursors of tissue macrophages and are central to a number of immunological responses, including cell-mediated cytotoxicity (Hibbs et al., 1977; Kleinerman. et al., 1983) and the production of inflammatory mediators (Le and Vilček, 1987). Peripheral blood is the main source of human monocytes for the investigation of their biological properties, but their isolation can be troublesome. The cells can be separated by their ability to adhere to plastic (David, 1975; Dayer, et al., 1979; Treves, et al., 1980 ), but the process of cell adherence potentially alters cell functional responses and detachment from the surface often results in loss of viability.

Correspondence to: M.C.M. Vissers/J.C. Fantone, Department of Pathology/Box 0602, The University of Michigan Medical School, 1301 Catherine Road, Ann Arbor, MI 481090602, U.S.A.

Abbreviation: PBS, phosphate-buffered saline.
The most successful methods of preparing monocytes in suspension also have disadvantages. Counterflow centrifugation (Sanderson et al., 1977; Norris et al., 1979) requires expensive equipment and is time-consuming, while centrifugation through Percoll gradients (Fluks, 1981; Hardin and Downs, 1981) often results in diminished yields.

Sepracell-MN, a colloidal silica cell separation medium for the isolation of peripheral blood lymphocytes and monocytes in suspension, has recently become available. When used as outlined by the manufacturer, viable monocytes can be isolated in a two-step procedure. However, considerable quantities of pre-packaged medium are required, and purification of monocytes from larger volumes ( $>100 \mathrm{ml}$ whole blood) becomes expensive and less practical. We describe a method for the purification of peripheral blood monocytes in suspension, which combines separation on FicollHypaque with centrifugation through Sepracell$\mathrm{MN}$, and which requires only a small amount of medium. 


\section{Materials and methods}

\section{Materials}

Ficoll 400 was purchased from Pharmacia Fine Chemicals, Uppsala, Sweden, and Hypaque (50\% w/v) from Winthrop-Breon Laboratories, Division of Sterling Drug, New York, NY 10016. Sepracell-MN $\left(1.099 \mathrm{~g} / \mathrm{cm}^{3}\right)$ was from Sepratech Corporation, 305 N. MacArthur Boulevard, Suite 100, Oklahoma City, OK 73127, and was obtained either in $15 \mathrm{ml}$ sterile tubes, each containing 6.7 $\mathrm{ml}$ Sepracell medium (15 g silica/100 ml Hepesbuffered saline), or in bottles containing $30 \mathrm{~g}$ silica $/ 100 \mathrm{ml}$ Hepes-buffered saline. Gelatin was from Difco Laboratories, Detroit, MI. Other biochemicals and reagents were from Sigma Chemical Co., St. Louis, MO.

\section{Isolation of monocytes}

Human peripheral blood, collected using sodium citrate as anti-coagulant (heparin and EDTA have also been used as anti-coagulants), was diluted with an equal volume of $0.9 \%(\mathrm{w} / \mathrm{v})$ $\mathrm{NaCl}$, layered onto a cushion of Ficoll-Hypaque $(1.077 \mathrm{~g} / \mathrm{ml})$ and centrifuged at room temperature for $30 \mathrm{~min}$ at $400 \times g$ (Böyum, 1968). The mononuclear cells were collected from the interface and washed twice with $20 \mathrm{mM}$ phosphate buffer, $\mathrm{pH}$ 7.4 , containing $138 \mathrm{mM} \mathrm{NaCl}$ and $2.7 \mathrm{mM} \mathrm{KCl}$ (PBS). The cells were resuspended in a small volume of PBS and either $3.4-3.5 \mathrm{ml}$ were added to a $15 \mathrm{ml}$ Sepracell-MN tube containing $6.7 \mathrm{ml}$ medium of composition $15 \mathrm{~g}$ silica $/ 100 \mathrm{ml}$ Hepes-buffered saline, or $2.7-2.8 \mathrm{ml}$ cells were added to $6.7 \mathrm{ml}$ Sepracell of composition $30 \mathrm{~g}$ silica/100 ml Hepes-buffered saline. Separation of monocytes and lymphocytes was achieved by centrifugation at room temperature for $20 \mathrm{~min}$ at $2000 \times g$ in a swing-out rotor. The band of cells at the top of the tube was collected and washed once in PBS. Contaminating platelets were removed from the sample by washing three times in ice-cold PBS containing $0.1 \%$ gelatin (Eccles and Glauert, 1984). Finally, the cells were washed three times in PBS and counted using a hemocytometer. Viability was determined by trypan blue exclusion, and the percentage monocytes was estimated after staining a cytospin smear either with Wright'sGiemsa or for non-specific esterase, using $\alpha$-naphthyl acetate as substrate.

\section{Results}

Monocytes were purified from mononuclear cells separated on Ficoll-Hypaque by centrifugation through Sepracell-MN (Table I). All the mononuclear cells from $100 \mathrm{ml}$ of blood (up to $30 \times 10^{7}$ cells) could be separated with $6.7 \mathrm{ml}$ medium. A continuous density gradient was generated upon centrifugation and the cells resolved into two tight bands, one at the top of the tube and the other at the bottom, separated by a distance of $5.5 \mathrm{~cm}$. Collection of the fractions without cross-contamination was therefore easy. The top band contained most of the monocytes, while the lymphocytes and some monocytes were present in the bottom band (Table I). Cells collected from Sepracell-MN frequently contained as many as ten platelets/monocyte. These were mostly re-

TABLE I

PURIFICATION OF MONOCYTES FROM $100 \mathrm{ml}$ WHOLE BLOOD ON FICOLL-HYPAQUE AND SEPRACELL-MN

Results shown are from one experiment. Similar findings were obtained on four other occasions.

\begin{tabular}{|c|c|c|c|c|c|c|}
\hline & $\begin{array}{l}\text { Total cell } \\
\text { number }(\%)\end{array}$ & $\begin{array}{l}\text { Monocytes } \\
\text { (\%) }\end{array}$ & $\begin{array}{l}\text { Lymphocytes } \\
\text { (\%) }\end{array}$ & $\begin{array}{l}\text { Granulocytes } \\
\text { (\%) }\end{array}$ & $\begin{array}{l}\text { Monocyte } \\
\text { recovery (\%) }\end{array}$ & Viability \\
\hline $\begin{array}{c}\text { Ficoll-Hypaque } \\
\text { monolayer }\end{array}$ & $120 \times 10^{6}$ & 31 & 67 & 0.5 & - & $>99$ \\
\hline $\begin{array}{l}\text { Upper band on } \\
\text { Sepracell-MN }\end{array}$ & $44 \times 10^{6}$ & 90 & 10 & - & 92 & $>99$ \\
\hline $\begin{array}{l}\text { Lower band on } \\
\text { Sepracell-MN }\end{array}$ & $74 \times 10^{6}$ & 4 & 96 & - & 7 & $>99$ \\
\hline
\end{tabular}




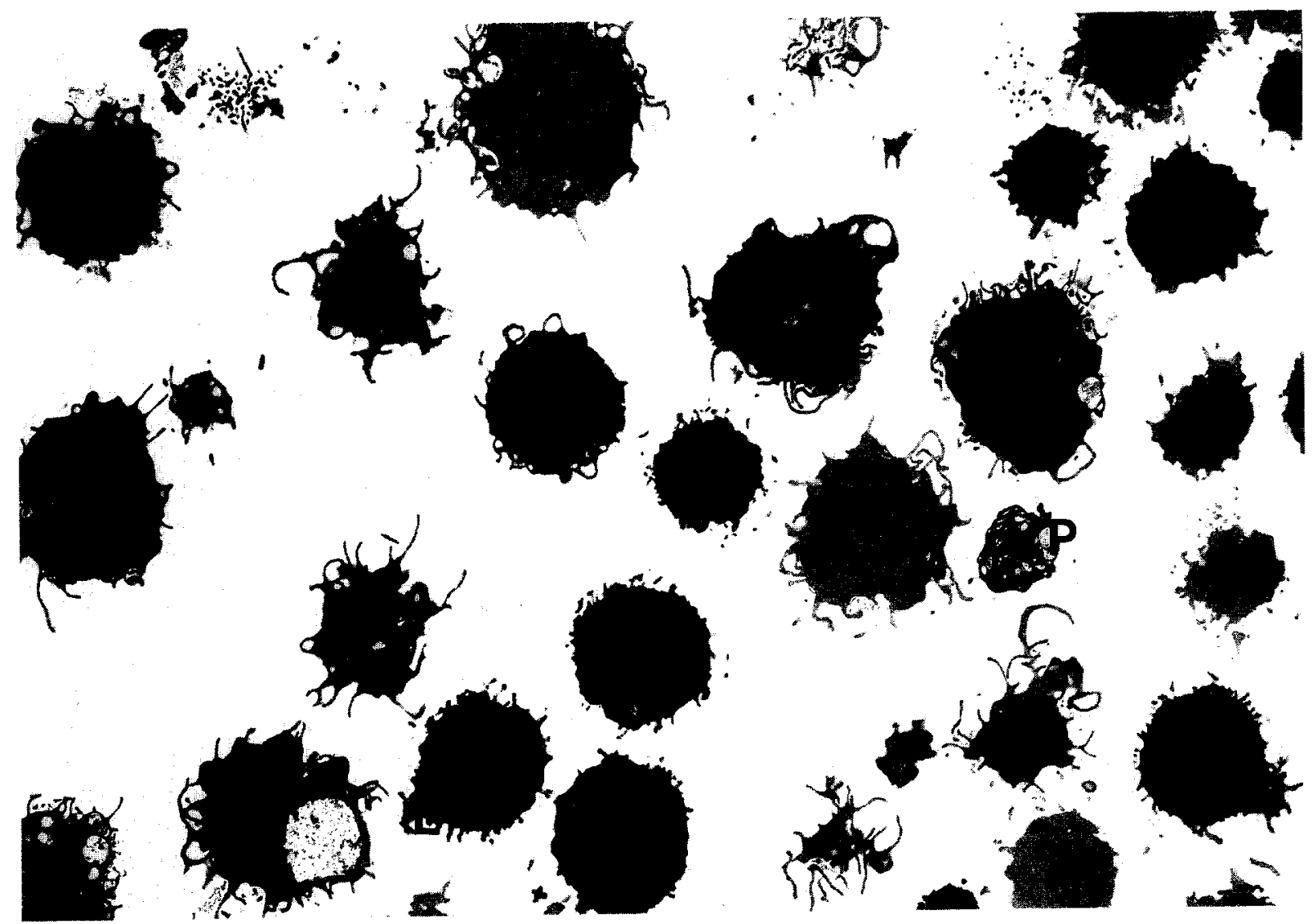

Fig. 1. A representative electron micrograph of cells isolated by centrifugation through Ficoll-Hypaque and Sepracell-MN. Most of the cells were monocytes $(\mathrm{M})$, although lymphocytes $(\mathrm{L})$ and platelets $(\mathrm{P})$ were also seen. Original magnification was $3300 \times$.

moved by washing at $4^{\circ} \mathrm{C}$ in $0.1 \%$ gelatin, which reduced the number to $0.2 \pm 0.2$ platelets/monocyte.

Final cell preparations contained mostly monocytes (Table II). The major contaminating cells were lymphocytes, with minimal numbers of

\section{TABLE II}

\section{COMPOSITION OF THE CELL POPULATION ISOLATED BY CENTRIFUGATION THROUGH FICOLL-HYPAQUE AND SEPRACELL-MN}

Mean \pm SD of 21 isolations are shown. The cells were identified after staining both with Wright's-Giemsa and for nonspecific esterase. In individual samples, agreement between the two methods of identification was within $3 \%$.

\begin{tabular}{lc}
\hline & $\%$ of total \\
Monocytes & $88 \pm 6$ \\
Lymphocytes & $12 \pm 7$ \\
Granulocytes & $0.6 \pm 1.3$ \\
\hline
\end{tabular}

TABLE III

EFFECT OF VOLUME ADDED TO SEPRACELL-MN ON THE SEPARATION AND RECOVERY OF MONOCYTES

Mononuclear cells obtained from Ficoll-Hypaque interface were resuspended in known volumes and mixed with one tube of Sepracell-MN. The number of monocytes present in the mononuclear cells was determined by staining for non-specific esterase, and the yield determined as recovery of monocytes loaded on to each tube.

\begin{tabular}{llll}
\hline $\begin{array}{l}\text { Volume added } \\
\text { to } 6.7 \mathrm{ml} \\
\text { Sepracell-MN a }\end{array}$ & $\begin{array}{l}\text { Monocytes } \\
\text { (\% of total) }\end{array}$ & $\begin{array}{l}\text { Lymphocytes } \\
\text { (\% of total) }\end{array}$ & $\begin{array}{l}\text { Monocyte } \\
\text { yield (\% of } \\
\text { cells loaded) }\end{array}$ \\
\hline 4 & 84 & 17 & 29 \\
3.5 & 92 & 8 & 75 \\
3 & 71 & 29 & 93 \\
\hline
\end{tabular}

a This experiment was carried out with Sepracell containing 15 $\mathrm{g}$ silica $/ 100 \mathrm{ml}$. A similar dependence of volume on purity and yield of monocytes was obtained when Sepracell containing 30 $\mathrm{g}$ silica $/ 100 \mathrm{ml}$ was used, with optimal separation at $2.7-2.8$ $\mathrm{ml} / 6.7 \mathrm{ml}$ medium. 
granulocytes (usually eosinophils) or (basophils) (Table II). Viability was always $\geqq 99 \%$ and the cells showed good functional ability to adhere and spread on plastic or immunoglobulin G-coated surfaces, to undergo a respiratory burst, degranulate and to release tumor necrosis factor and interleukin-I when stimulated (Vissers, Wiggins, Fantone and Kunkel, submitted for publication). Electron micrographs showed cells with good morphology having intact cytoplasmic granules and organelles, and occasional cells with mild ruffling of the cell membrane (Fig. 1). There was no evidence of phagocytosis of Sepracell beads, as is sometimes seen when monocytes are isolated using Percoll, which also consists of silica particles. Phagocytic vacuoles containing amorphous material were sometimes seen (Fig. 1). This was most likely gelatin, and this could be avoided by ensuring that washing with gelatin was carried out at $4^{\circ} \mathrm{C}$.

Resolution of the monocytes on Sepracell-MN was dependent upon the volume in which the cells were added (Table III). When more than $3.5 \mathrm{ml}$ was added, less monocytes were recovered, and when smaller volumes were added, more lymphocytes were present in the top band. Dilution of 6.7 ml Sepracell-MN with $3.4-3.5 \mathrm{ml}$ resulted in a good compromise between recovery and purity of monocytes. Recovery of cells was very good, averaging around $80 \%$ of the monocytes loaded onto the Sepracell-MN. The mean yield from $100 \mathrm{ml}$ of blood was $49 \times 10^{6} \pm 21 \times 10^{6} \quad(n=34)$, and the range was between 14 and $92 \times 10^{6}$. The normal range of monocyte levels in $100 \mathrm{ml}$ human blood is between 9 and $100 \times 10^{6}$. Thus, the yield of monocytes in our preparations fell within the expected range from a pool of normal donors.

\section{Discussion}

We have developed a rapid, convenient, and relatively inexpensive method for the isolation of human peripheral blood monocytes in suspension. By first separating the mononuclear cells in Ficoll-Hypaque, the monocytes from up to $100 \mathrm{ml}$ blood can be purified using only one $6.7 \mathrm{ml} \mathrm{Sep}$ racell-MN. If the standard Sepracell-MN method were used, then approx. $200 \mathrm{ml}$ would be required to separate the monocytes from an equivalent amount of blood, and this would involve considerable handling and expense. Our modification, therefore, offers a considerable financial advantage, and is also more convenient.

This method has several advantages over other means of preparing monocytes. It is simpler than counterflow centrifugation, which requires expensive equipment, is time-consuming and difficult to carry out in sterile conditions, and it is more reliable than removal of cells adherent to plastic, which usually results in decreased viability. Sepracell-MN is also easier to use than Percoll since it does not require pre-formation of a gradient and produces a good monocyte yield.

The isolated monocytes were not only viable as assessed by trypan blue exclusion, but also showed good functional responsiveness. Since not all the monocytes loaded onto Sepracell-MN were recovered $(<10 \%$ of the total were present in the bottom layer), it is possible that this selects out the smaller, denser cells. We have used monocytes isolated on Ficoll-Hypaque and Sepracell-MN to investigate phagocytic responses, as well as cytokine production, with excellent results and good reproducibility (Vissers, Fantone, Wiggins, Kunkel, submitted for publication). This method, therefore, provides a simple and inexpensive means of isolating human peripheral blood monocytes for the study of their biological properties.

\section{References}

Böyum, A. (1968) Isolation of mononuclear cells and granulocytes from human blood. Isolation of mononuclear cells by one centrifugation; and of granulocytes by combining centrifugation and sedimentation at $1 \mathrm{~g}$. Scand. J. Clin. Lab. Invest. 21 (suppl. 97), 77.

David, J.R. (1975) Macrophage activation by lymphocyte mediators. Fed. Proc. 34, 1730.

Dayer, J.M., Breard, J., Chess, L. and Krane, S.M. (1979) Participation of monocytes macrophages and lymphocytes in the production of a factor that stimulates collagenase and prostaglandin release by rheumatoid synovial cells. $\mathbf{J}$. Clin. Invest. 64, 1386.

Eccles, M.H. and Glauert, A.M (1984) The response of human monocytes to interaction with immobilized immune complexes. J. Cell. Sci. 71, 141.

Fluks, A.J. (1981) Three-step isolation of human blood monocytes using continuous density gradients of Percoll. J. Immunol. Methods 41, 225. 
Hardin, J.A. and Downs, J.T. (1981) Isolation of human monocytes on re-orienting gradients of Percoll. J. Immunol. Methods 40, 1.

Hibbs, J.B., Taintor, R.R., Chapman, H.A. and Weinberg, J.B. (1977) Macrophage tumor killing: influence of the local environment. Science 197, 279.

Kleinerman, E.S., Schroit, A.J., Fogler, W.E. and Fidler, I.J. (1983) Tumoricidal activity of human monocytes activated in vitro by free and liposome-encapsulated lymphokines. J. Clin. Invest. 72, 304.

Le, J. and Vilcek, J. (1987) Tumor necrosis factor and interleukin-1: Cytokines with multiple overlapping biological activities. Lab. Invest. 56, 234.
Norris, D.A., Morris, R.M., Sanderson, R.J. and Kohler, P.F. (1979) Isolation of functional subsets of human peripheral blood monocytes. J. Immunol. 123, 166.

Sanderson, R.J., Shepperdson, F.T., Vatter, A.E. and Talmage, D.W. (1977) Isolation and enumeration of peripheral blood monocytes. J. Immunol. 118, 1409.

Treves, A.J., Yagoda, D., Haimovitz, A., Ramu, N., Rachmilewitz, D. and Fuks, Z. (1980). The isolation and purification of human peripheral blood monocytes in cell suspension. J. Immunol. Methods 39, $7 \dagger$. 